Artículo Científico Original

César Augusto Baldi

\title{
DESCOLONIZANDO \\ O ENSINO DE DIREITOS HUMANOS?
}




\section{DESCOLONIZANDO \\ O ENSINO DE DIREITOS \\ HUMANOS?}

\section{DECOLONIZING \\ THE HUMAN RIGHTS \\ EDUCATION}

\section{César Augusto Baldi}

Mestre em Direito (ULBRA/RS), doutorando Universidad Pablo Olavide (Espanha), servidor do TRF-4 Região desde 1989,é organizador do livro "Direitos humanos na sociedade cosmopolita" (Ed. Renovar, 2004).

\section{RESUMO}

É possível pensar os direitos humanos em chave descolonial? A trajetória de seu reconhecimento é universal, universalizável ou oculta outras trajetórias de lutas? Neste sentido, pensam-se seis pontos para repensar a questão: a) as distintas modernidades europeias, incluindo o período ibérico; b) o processo revolucionário, para além das revoltas burguesas, incluindo outras insurreições antissistêmicas; c) a influência da diáspora africana e da escravidão para repensar o sofrimento humano ocultado; d) a segunda onda de descolonização dos países, em especial africanos e asiáticos, que põe na agenda internacional a luta pela independência e a reconfiguração de outras tradições não europeias; e) a utilização de novas técnicas, como literatura, cinema e artes visuais, abrindo campo para experimentação de visões alargadas de direitos humanos; f) a antropologia dos sentidos, de tal forma que os cinco sentidos sejam utilizados para dar novos sentidos à temática de direitos humanos.

Palavras-chave: Descolonização - Modernidades - Eurocentrismo - Diáspora Africana - Antropologia dos Sentidos.

\section{ABSTRACT}

Is it possible to think about human rights in a decolonial key? The trajectory of its recognition is universal, universable or it hides another trajectories of fights? Based on that - another six points are thought to reissue the question: a) The different European modernities, including the Iberian period; b) The revolutionary process beyond bourgeois revolts, including other insurrections against the system; c) The influence of the African diaspora and slavery to rethink the hidden human suffering; d) The second wave of decolonization - the asian and african coutries, that put the struggle for independence and the reconfiguration of another non european tradition e) The use of new techniques such as literature, film and visual arts, opening the field for extended experimentation with human rights visions; f) Anthropology of senses, so that the five senses can be used to provide directions to a new topic of human rights

Keywords: Decolonization - Modernities - Eurocentrism - African Diáspora Anthropology of Senses. 


\section{INTRODUÇÃO}

Segundo a nova Constituição boliviana, a educação, "função suprema e primeira responsabilidade financeira do Estado", é unitária, pública, universal, democrática, participativa, comunitária, descolonizadora e de qualidade (art. 78, I), e, em todo o sistema educativo, "intracultural, intercultural e plurilíngue"(art. 78, II), no sentido de que "a interculturalidade é o instrumento para a coesão e convivência harmônica e equilibrada entre todos os povos e nações"(art. 98).

A Constituição brasileira assume o "pluralismo de ideias e de concepções pedagógicas", no campo educativo (art. 206, III), e a proteção de direitos culturais, acesso a fontes da cultura da cultura nacional e proteção das "manifestações dos grupos participantes do processo civilizatório nacional", no campo da cultura (art. 215, caput e $\S 1^{\circ}$ ). Mas até que ponto, efetivamente, outros saberes- afro-ameríndios, de populações tradicionais, etc- não continuam a ser silenciados, oprimidos, ocultados e tidos como inexistentes? É possível afirmar que ao apregoado pluralismo de ideias corresponde uma justiça cognitiva?

Talvez fosse interessante fazer um exercício similar, analisando como os direitos humanos são tematizados e ensinados nos cursos regulares. Naquela versão que se tornou hegemônica, a preocupação é geracional: direitos civis e políticos; sociais, econômicos e culturais; terceira geração; e quiçá uma quarta (democracia) ou quinta.

\section{Contextualizando...}

Mas esta trajetória é universal, universalizável ou simplesmente oculta trajetórias de lutas por direitos humanos contra ○ próprio projeto de modernização? Recorde-se, que a Revolução Francesa, tida como um momento da consolidação da liberdade, igualdade e fraternidade, não reconheceu direito às mulheres tampouco questionou a escravidão da população negra.

Deve-se considerar, ainda, que, à época da Declaração, apenas 48 votaram a favor, nenhum contra e 8 se abstiveram (África do Sul, Arábia Saudita, URSS, Bielorrússia, Tchecoslováquia, Polônia, Ucrânia, lugoslávia). Hoje em dia, com o Sudão do Sul, são 193 países no sistema ONU. A maior parte dos países- e isso, no geral, não se salienta- eram justamente colônias de vários dos países europeus que assinaram a Declaração. Tanto que a Declaração deveria ter sido assinada junto com as duas convenções (os denominados pactos de direitos civis e políticos, ao lado de econômicos, sociais e culturais), bem como da relativa ao genocídio. Somente o primeiro pacto foi assinado e- no geral, também se esqueceque, apesar do sistema ONU afirmar o direito à autodeterminação dos povos, o art. II.2 da Declaração fala em território "sob tutela, sem governo próprio" ou "sujeito a outra limitação de soberania". Porque, de fato, a declaração descolonial será aquela assinada em 1960, que inicia o processo de libertação dos povos africanos e asiáticos do domínio europeu ( praticamente, somente a Tailândia não foi colônia formal em algum período histórico "moderno").

Mas não se pode esquecer que o exercício de autodeterminação invisibilizou, também, os colonizados internos, os indígenas de todos os países, condição que foi parcialmente reconhecida pela Convenção 169 da OIT e, finalmente, em 2007, com a Declaração das Nações Unidas sobre os direitos dos povos indígenas. E mesma esta declaração é trabalhada pelo signo colonial: a) primeiro, ao não se recordar tratar-se de um documento discutido durante mais de 30 anos não somente pelos 
países, mas, fundamentalmente, pelos próprios povos indígenas, o que lhe acarreta um patamar de legitimidade jurídico muito superior a vários outros instrumentos internacionais; b) segundo, porque se trata de documento de tipo novo, como destacado por Bartolomé Clavero (CLAVERO, 2008), mais que uma declaração tradicional e pouco menos que uma convenção, ao prever nos arts. 38 e 42 mecanismos de supervisão parcial de seus artigos e pela imperatividade, em sua formulação, dos direitos enunciados. A manutenção da visão colonial na leitura de um texto descolonial é um ponto a ser ressaltado. E vai ser onde será declarada, de forma evidente, o "direito à cultura".

Como recorda Clavero (CLAVERO, 2009), é necessário que a declaração de 2007 afirme, com todas as letras, que os indígenas também tem direitos humanos. Um paradoxo que pode-se verificar, por exemplo, tanto na Convenção de Belém do Pará quanto da Lei Maria da Penha, ao afirmar que as mulheres tem direitos humanos iguais a todas as pessoas. que mostra, portanto, não somente um viés colonial, mas também eurocentrado, heteronormativo, sexista, masculino do texto. Aliás, em termos de linguagem, a Constituição do Equador, de 2009, será a primeira a citar todos os seus artigos em linguagem não sexista- "os homens e as mulheres", "os equatorianos e equatorianas", o "presidente ou presidenta", etc.

A Declaração de 1948 é, nesse sentido, um signo colonial europeu e aplicado parcialmente ao mundo então existente. Trabalhos mais recentes, como a monumental coletânea de José Manuel Barreto (Human Rights from Third World perspective. Cambridge, 2013) tem levantado outras informações sobre o processo de discussão do documento então aprovado, mostrando as tensões internas e também a contribuição de países latino-america- nos e do Líbano na construção do consenso então realizado. Neste sentido, o "rotundo sim" se converte em "parcial não". Estas outras matrizes discursivas foram invisibilizadas com a predominância da presença de Maritain e Eleonor Roosevelt no processo (vide, no livro citado, as contribuições de Glenn Mitoma e de Susan Waltz). E se a Declaração em seus "consideranda" destaca os atos bárbaros do nazismo, ela o faz, no mesmo instante, ocultando duas questões vinculadas aos alegados campeões de direitos humanos, os Estados Unidos: a) manutenção do sistema de segregação racial, que impediria a vigência, na prática e de forma cruel, da igualdade de todas as pessoas "independentemente de raça e cor" (art. II.1); b) a extrema violência que foi, no final da Segunda Guerra, o bombardeio de Hiroxima e Nagasaki, no Japão. Esta ocultação é tão impressionante que, muitas vezes, como me recordou Walter Mignolo, passa despercebida.

Proponham-se, pois, alguns outros temas e revoltas para questionar, descolonizar, pluralizar e ressaltar a necessidade da interculturalidade.

\section{Distintas modernidades europeias.}

privilégio epistemológico outorgado ao lluminismo concentrou as atenções na segunda modernidade (Inglaterra, França e Holanda), em detrimento do período do Renascimento e de toda a primeira modernidade (Itália, Portugal e Espanha). Daí porque a discussão sobre os "direitos do homem" seja salientada, mas a polêmica sobre "quem conta como humano" seja esquecida: a disputa entre Sepúlveda e Bartolomé de las Casas sobre os direitos dos índios é um bom exemplo.

Mas a própria produção latino-americana foi ignorada, como mostra o resgate de Guaman Poma de Ayala. Este 
descendente inca escreveu um tratado sobre o bom governo, em que critica a monarquia; desenvolve novo sistema de governo (mescla de seus conhecimentos sobre a sociedade espanhola e a inca), antecipando a "divisão de poderes" e produz uma rica iconografia profundamente questionadora da ordem colonial (MIGNOLO, 2008, 304-307). Do que se trata, portanto, é também do reconhecimento da existência de uma "diferença imperial"(MIGNOLO, 2003, 440-443), que ficou evidente, recentemente, com a utilização por França e Alemanha da expressão PIGS ("porcos", literalmente), para referir-se às crises econômicas de Portugal, Itália, Grécia e Espanha ("Spain"), ou seja, o Sul do Norte.

\section{Revoluções burguesas e insurreições anti sistêmicas.}

Se naquele momento, os indígenas foram considerados como portadores de alma ("privilégio" que os negros escravizados não tiveram reconhecidos nem pela Igreja Católica, nem pelos movimentos revolucionários burgueses), o fato é que a narrativa dos direitos humanos salientou somente as revoluções burguesas (em especial a francesa e a estadunidense). Concomitante à denominada "era das revoluções" (1789-1848), eclodiam, na hoje denominada América, duas insurreições "silenciadas". Por um lado, a Revolução Haitiana (1804), que se torna a primeira nação negra, de escravos iletrados, a se tornar independente e abolir a escravidão e estabelecer, dentre outros, direitos iguais para filhos nascidos fora do matrimônio, a possibilidade de divórcio. Por outro lado, o movimento de Tupac Katari (1780-1781) e Bartolina Sisa, na Bolívia, contra o domínio espanhol. Um ideário de luta que, se valendo da palavra aimara "pachakuti" (o "mundo ao revés") indica, de forma mais interessan- te, o sentido original da própria palavra "revolução" (a volta que os astros celestes dão para completar seu ciclo) (TICONA ALEJO, 201 1). Não são, portanto, as lutas de independência protagonizadas por "criollos" e celebradas pelos inúmeros "bicentenários", mas movimentos de oprimidos negros e indígenas contra os fundamentos do sistema colonial e sua superação. E sem os quais, no caso do último, a Revolução de 1952, as guerras do gás e da água (2003), a discussão sobre direitos da natureza, o protagonismo indígena e também a discussão realizada por Fausto Reinaga (1906-1994) (TICONA ALEJO, 2013), intelectual aimara, ficam dificilmente inteligíveis.

\section{Diáspora africana e a escravidão.}

No século XVII, diversas narrativas de negros libertos questionando a escravidão, a "vida de nenhum significado", a necessidade do reconhecimento da dignidade de todos independentemente de raça e origem geográfica estiveram disponíveis para estudo. Por que elas são esquecidas, como se a escravidão fosse um mero acidente de percurso na modernidade e não a face perversa da "colonialidade do poder"? Por que os livros tratam da história da França sem considerar a inter-relação com as colônias, mas a história destas é lembrada como dependente da metrópole? Como imaginar que um sistema que, no Brasil, durou mais de 400 anos (e o país não é independente nem há 200), é um acontecimento de pouca importância e não um "crime contra a humanidade" (Declaração de Durban) e- mais que istoconstitutivo do sistema moderno? A colonialidade é a outra face da modernidade, e isto não se quer reconhecer.

Ottobah Cugoano (1757-1791), nascido em Gana e educado na Inglaterra, vai não somente apresentar propostas para 
terminar com a escravidão, mas também para compensar as nações africanas pelos danos ocorridos e para legalizar o trabalho. Para ele, os seres humanos são iguais e livres "perante outros seres humanos e não perante o Estado" (CUGOANO, 1999). No mesmo sentido, o relato de Olaudah Equiano (1745-1797).

E que dizer de Sojourner Truth (17971883), que vai criticar não somente a desigualdade racial, mas também aquela com relação às mulheres, no momento em que a cultura dos EUA colocava as mulheres brancas em pedestal, mas ignorava as mulheres negras?

Em um discurso de 1852, ela afirma (TRUTH, 2014):

Aqueles homens ali dizem que as muIheres precisam de ajuda para subir em carruagens, e devem ser carregadas para atravessar valas, e que merecem $\circ$ melhor lugar onde quer que estejam. Ninguém jamais me ajudou a subir em carruagens, ou a saltar sobre poças de lama, e nunca me ofereceram melhor lugar algum! E não sou uma mulher? Olhem para mim? Olhem para meus braços! Eu arei e plantei, e juntei a colheita nos celeiros, e homem algum poderia estar à minha frente. E não sou uma mulher?

E depois mais ainda: "Daí aquele homenzinho de preto ali disse que a mulher não pode ter os mesmos direitos que o homem porque Cristo não era mulher! De onde o seu Cristo veio? De onde o seu Cristo veio? De Deus e de uma mulher! O homem não teve nada a ver com isso". Que se tem nesse caso? Primeiro, a oralidade de um relato frente à "racionalidade da escritura" de vários textos clássicos do feminismo branco, uma oratória aprendida nos púlpitos das igrejas. Segundo, uma mulher negra iletrada que, sem ter uma obra escrita, se conecta com as lutas de mulheres negras e contra o racismo. Terceiro, um texto criado a partir de um olhar "desde a colonialidade": ela desconstrói a categoria (hegemônica) de mulher para reivindicar sua própria identidade enquanto mulher e negra. A intersecção raça e gênero que é usada para construir as mulheres negras como "não mulheres" é usada, aqui, contra hegemonicamente como categoria inclusiva, invertendo o discurso. Um discurso não somente abolicionista, mas também de defesa dos direitos das mulheres.

\section{Segundo processo de descolonização.}

No momento em que se passaram cinquenta anos da Declaração de descolonização da ONU (1960), a importância das lutas de asiáticos e africanos no processo de instauração de direitos humanos após a Segunda Guerra Mundial merece ser reavaliada. Não somente os líderes do processo (Nyerere, Samora Machel e outros). Também as contribuições de Fanon, Glissant e Césaire, dentro de uma perspectiva negra, e todas as contribuições que tem sido feitas no âmbito asiático (de que os "estudos subalternos" da Índia são apenas uma parcela) e, porque não salientar, aquelas que não têm matriz marcadamente secular, como o "feminismo islâmico" ou mesmo o movimento de "feminismo indígena".

Não é demais lembrar que o secularismo, nas colônias, serviu aos propósitos coloniais de submissão da mulher. Joan Scott mostra isso, de forma muito interessante, num texto em que ela faz um jogo de palavras"sexularism", no auge das discussões sobre o véu na França (SCOTT, 2009). O que fazem estas feministas? Querem trabalhar, dentro de um referencial islamicamente centrado, novas versões inclusivas de di- 
reitos das mulheres (BALDI, 2011). Amina Wadud e Asma Barlas, a partir de leituras do Corão, Kecia Ali revisitando a jurisprudência dos distintos países, Sadiyya Shaikh recuperando a conexão entre espiritualidade e sexualidade nos escritos de Ibn Arabi são algumas destas representantes. A ONG Baobah, na Nigéria, e a Sisters in Islam, na Malásia, da mesma forma que Musawah ("igualdade", em árabe) conseguiram importantes vitórias legislativas e de lutas a favor das mulheres, utilizando um referencial islâmico. A aprovação da Moudawana, o código de família do Marrocos, foi uma aliança entre feministas seculares e islâmicas, e toda a fundamentação das diretrizes de igualdade entre homens e mulheres está expressa- na apresentação- em termos de jurisprudência islâmica ou do Corão. O fato é que, muitas vezes, a injustiça cognitiva também aqui se faz presente. Escolhem-se determinadas interlocuções com pessoas que estejam dentro deste olhar colonial, imperialista, sexista que vai olhar africanos e asiáticos, ou mesmo russos, como "bárbaros", não "civilizados". Diversas lutas têm sido invisibilizadas desta forma. Por isso, o último livro de Lila Abu-Lughod tem o significativo título- "Do Muslim Women Need Saving?" (Harvard University Press, 2013).

Samuel Moyn (MOYN, 20010) tem salientado bastante a ilusão teleológica de fazer uma leitura da história da frente para trás, como se o consenso sobre direitos humanos hoje existente confirmasse um caminho linear. $E$, neste ponto, a escolha dos precursores é crucial. Recentemente, Saba Mahmood (MAHMOOD \& DANCHIN, 2014) organizou um número temático da "South Atlantic Quarterly" e mostra, por exemplo, que existem distintas genealogias para a liberdade de religião e que hoje elas estão em disputa, seja nas discussões do "laicismo" na França, seja nos movimentos fundamentalistas religiosos, seja na jurisprudência da Corte Europeia de Direitos Humanos. Quando se discutem direitos humanos, a questão do secularismo e- mais que isso, sua própria descolonização- é por demais importante, para não ser questionada. Este pós-colonialismo, contudo, é de matiz distinto daquele resultado do primeiro processo descolonial (independências das Américas) e devem ser observadas suas diferenças.

\section{Utilização de outras técnicas}

Tem sido comum a utilização de literatura, cinema e artes visuais para a discussão dos direitos humanos, o que é salutar, na medida em que a racionalidade estético expressiva, durante muito tempo, ficou colonizada pela racionalidade jurídica e científica. É necessário, contudo, que não somente o meio utilizado seja alterado: do que se trata é de mudar os termos do próprio debate. Não diz respeito somente aos conteúdos, mas à própria enunciação. Antígona, por exemplo, vem sendo usada, nos cursos jurídicos, para estabelecer uma oposição entre jusnaturalismo e positivismo, uma discussão europeia que fora salientada por Hegel, no século XVIII. Que tal utilizar a "trilogia tebana", como fez Judith Butler (BUTLER, 2001), para discutir o "parentesco aberrante" (afinal, Antígona é filha de Édipo e de Jocasta, sua avó), a heteronormatividade, o sexismo e o patriarcado? O que seria destas questões se, ao invés de um "complexo de Édipo", o debate fosse reconfigurado a partir de um "complexo de Antígona" (STEINER, George Steiner)?

\section{A antropologia dos sentidos e os sentidos dos direitos humanos.}

É preciso que os sentidos (visão, olfato, paladar, tato e audição), sejam sentidos (enquanto "sentire"), de forma a darem novos sentidos (enquanto direções) para enten- 
dimento de direitos humanos. $E$ isso vale para repensar conhecimentos a partir de outras comunidades de "intérpretes".

Uma alternativa, contudo, não vem sendo explorada. Afinal, a "descolonização" dos sentidos altera o entendimento e a formulação de nossas lutas contemporâneas? E que dizer, por exemplo, de um feminismo indígena, assentado numa epistemologia aimará, que, conforme salienta Silvia Rivera, está centrada no "escutar" a "Pachamama" (mãe terra) e não mais na "visão"?

Talal Asad (ASAD, s.d) tem salientado ser necessário realizar "etnografias do corpo humano", pesquisas sobre suas atitudes "em relação à dor, danos físicos, decomposição, morte, bem como integridade física, crescimento e prazer", e também "condições que isolam pessoas e coisas entre si ou que as conectam fortemente com outros".

Desta forma, portanto, seria necessário perguntar que atitudes particulares e sensibilidades dependem de determinados sentidos e como "novas percepções sensoriais tomam corpo e tornam irrelevantes velhos modos de se relacionar com o mundo (experiências mais antigas) e veIhas formas políticas." Uma análise que, segundo ele, envolve um campo teórico de interpretação para "ajudar a identificar os sentidos e suas expressões", sendo certo que os "sentidos, em si mesmos, não necessariamente requerem significados", ou seja, "sem ter que interpretar nada."

Dentro da tradição religiosa islâmica, Talal Asad destaca, por exemplo, que os sentidos da audição e da visão, e, pois, ler e recitar estão intimamente entrelaçados. Assim, o Corão (que significa "recitação"/"leitura") é profundamente "enraizado em complexas continuidades- inteiramente separados das maiores escolas de interpretação que providenciaram seus significados", de modo que
- "texto antigo, escrita na forma textual do sétimo século, tem sido tratado como uma forma de marcação melódica/musical, um lembrete para a tradução oral que depende da memorização através da reiteração". Com isso:

Signo e som caminham juntos, mas não de algum modo fixo e direto. Somente porque as tradições orais foram contínuas que eles são hábeis de providenciar um quadro imanente para o texto escrito, e, assim, para sua recepção erudita através dos séculos. Um esforço, pois, é sempre requerido para abstrair ○ texto corânico como um objeto de interpretação intelectual de suas relações entre sons carregados e a atenção do corpo, com seu crescente armazenamento de memorizações.

Alain Corbin, por sua vez, também vem analisando as mudanças de percepção do mundo apropriadas pelos diversos sentidos, sem estarem, inicialmente, vinculadas com interpretações. Salienta que as condições de contágio de doenças e as práticas de higiene individual nos séculos XVIII e XIX na sociedade francesa, se, por um lado, indicam o olfato como "superior" quando se "trata de medir a renovação do ar e, portanto, de prever os danos do apinhamento", por outro, acarretam o aumento da preocupação com a luminosidade, o "primado inconteste do visual". Destaca uma "mutação sensorial nas elites e a maré discursiva que ela suscita", para afirmar que "o fato histórico essencial não é uma realidade que quase não mudara, mas, antes, uma percepção nova, uma nova intolerância de uma realidade tradicional." (CORBIN, 1987, p. 198-201).

Ele nota que, no final do século XVIII, os perfumes baseados em animais, tais como almíscar, zibeta e âmbar, eram usados 
pelas mulheres, não para mascarar seus odores próprios, mas para enfatizá-los, e passam, no século XIX, em função das novas considerações sobre higiene pessoal, a serem desacreditados em favor de "disfarçar com habilidade cada vez maior os odores corporais tornados inoportunos", negando o "papel sexual do olfato", cabendo, a partir de então, "às delicadas exalações da perspiração, e não mais aos odores das secreções, pressagiar a ligação íntima". Uma forma, pois, de disfarçar os odores do corpo, ao mesmo tempo que evoca discretas intimidades do feminino. Daí a substituição por "óleos essenciais" e "águas de cheiro", retirados de flores primaverais ( são as águas de rosas, de violeta, do tomilho, da lavanda e do alecrim). (CORBIN, 1987, p. 99-101).

Ao mesmo tempo, são os lugares íntimos, "de monólogo interior", que garantem a "disponibilidade olfativa do quarto e da sala de jantar", permitindo a "emergência de uma estética do olfato"e, pois, uma "arte dos aromas destinados a ornar os lugares da intimidade acompanha os tímidos progressos da perfumaria", e o "quarto individual, que se trata de desodorizar, simboliza esse processo" como "local por excelência da intimidade olfativa" (CORBIN, 1987, p. 217)

Daí a observação de Talal Asad de que "atitudes e sensibilidades são deliberadamente cultivados pelas instituições e movimentos sociais", mas, os sentidos são "centrais para a vida pública em que as pessoas participam, para os modos que ela promove, se submete, resiste ou permanece indiferente às forças da vida política."(ASAD, s.d)

\section{Considerações finais: a questão da justiça cognitiva.}

Para Boaventura Santos, o colonialismo foi também uma "dominação epistemológi- $\mathrm{ca}$, uma relação extremamente desigual entre saberes que conduziu à supressão de muitas formas de saber próprias dos povos e nações colonizados, relegando muitos outros saberes para um espaço de subalternidade." (SANTOS \& MENESES, 2010, p. 11).

O sociólogo indiano Shiv Visvanathan vai desenvolver a ideia de justiça cognitiva, ou seja, "o direito de diferentes formas de conhecimento coexistirem sem serem marginalizadas pelas formas de conhecimento oficiais, patrocinadas pelo Estado", buscando, assim, "uma viva ecologia de saberes, como expressa, por exemplo, no debate entre sistemas indígenas e a nova medicina, na Índia, em 1923." (VISVANATHAN, s.d).

A questão envolve, pois, "o reconhecimento de conhecimentos outros que não a ciência, vistos não dentro das lentes da ciência ou dos testes de prova científica" mas como "modos de vida que têm sua própria validade cognitiva", o que demanda um espaço de "indiferença cognitiva em relação à ciência." (VISVANATHAN, 2009). Afinal, a narrativa do progresso é irônica, pois "uma sociedade que vê represas como templos da moderna Índia está agora de frente ao fato de que há mais refugiados dos projetos de desenvolvimento que de todas as guerras que foram travadas. (VISVANATHAN, 2008). Segundo ele (VISNATHAN, 2009):

a democracia como uma teoria da diferença tem que reconhecer não a validade universal da ciência, mas a plural disponibilidade de conhecimentos e que nenhuma foma de conhecimento possa ser museologizada e que a memória e inovação caminhem intrinsecamente juntas. A ideia de alternativas em ciência dá margem a ciências alternativas, a universalismos em competição. Tanto a crítica alterna- 
tiva, quanto a ludita, são agora vistas não como fundamentalismos, mas como outras formas de construir conhecimento. Existe um radical ponto de partida na política do conhecimento que nós devemos reconhecer. Voz, protesto, resistência, participação e direitos de não esgotar o quadro teórico da democracia. Para isso, necessitamos de uma democracia dos conhecimentos.

Desta forma, o conceito de justiça cognitiva reconhece o direito de "diferentes formas de conhecimento coexistirem", mas salienta que tal pluralidade necessita ir além da "tolerância ou liberalismo para um ativo reconhecimento da necessidade da diversidade", uma ecologia de saberes "onde cada conhecimento tem seu lugar, sua afirmação como cosmologia, seu sentido como forma de vida", conectando-se com o ciclo de vida, com o estilo de vida, com a subsistência. (VISVANATHAN, 2009). A pluralidade é, sob este ponto de vista, a garantia de que "soluções alternativas e caminhos alternativos para resolver problemas estão sempre disponíveis dentro de uma cultura." E a ideia de "justiça cognitiva" é inseparável da "imaginação democrática", onde

conversação, reciprocidade, tradução criam conhecimento não como um expert, quase uma soma zero do mundo, mas como uma colaboração de memórias, legados, heranças, uma heurística variada de resolver problemas, onde um cidadão tenha tanto poder quanto conhecimento em suas próprias mãos.

exercício de imaginação epistemológica e democrática é também de imaginação cartográfica, para ver em "cada escala de representação não só o que ela mostra, mas também o que ela oculta" e para "lidar com mapas cognitivos que operam simultaneamente com diferentes escalas", em especial detectar articulações locais e globais (SANTOS, s. d).

Mas também um processo de reinventar a imaginação jurídica, abrindo novas perspectivas de entendimento, para acoIher pluralismo de concepções, diálogos interculturais e novos exercícios de resolução das questões.

Syed Farid Alatas (ALATAS, 2010) e sua colega Vineeta Sinha (SINHA, 2003) vêm desenvolvendo, na National University of Singapore, há muitos anos, um estudo diferente de Sociologia: ao invés de somente analisar os "clássicos" Durkheim, Weber e Marx (homens brancos europeus), os alunos são instigados a trabalhar as contribuições de Ibn Khaldun (Tunísia), José Rizal (Filipinas), Benoy Kumar Sarkar (Índia) e Harriet Martineau (Inglaterra), dentre outr@s. Uma forma de mostrar, segundo eles, que havia "também mulheres brancas europeias, além de homens e mulheres não europeus e não brancos que, no século XIX, teorizaram sobre a natureza das sociedades modernas emergentes". Que tal começar um movimento similar no estudo dos dos direitos humanos? Talvez, aqui, se consiga vencer o "racismo epistêmico" e "mudar a geografia da razão"(GORDON, s.d). Ou, como diria Walter Benjamin ( $7^{a}$ tese sobre a história), "arrancar a tradição ao conformismo, que quer apoderar-se dela" e escrever uma "história a contrapelo"(BENJAMIN, s.d)

\section{REFERÊNCIAS BIBLIOGRÁFICAS}

ALATAS, S. F. 2010. A definição e os tipos de discursos alternativos. Estudos Históricos, Rio de Janeiro, 46: 225-245.

ASAD, T. Thinking about religions belief and politics. Disponível em http://iah.unc.edu/images/events/ EventDocuments/asadreligionpolitics, acessado em 08/06/2014. 
BALDI, C. A. 2011 . Secularismo, Islã e o "muçulmano": reflexões sobre colonialidade e biopolítica. Meritum, Disponível em http://www.fumec.br/ revistas/index.php/meritum/article/view/1077, acessado em 08/06/2014.

BENJAMIN, W. Teses sobre la historia y outros fragmentos. Disponível em http://www.bolivare.unam. $\mathrm{mx} /$ traducciones/Sobre $\% 20$ el\%20concepto $\% 20$ de\%20historia.pdf, acessado em 10/06/2014.

BUTLER, J. 2001. El grito de Antígona. Disponível em http://media.espora.org/mgoblin_media/ media_entries/511/Butler_Judith_-_El_Grito_ De_Antigona.pdf, acessado em 10/06/2014.

CLAVERO, B. 2009. No distinction shall be made. Disponível em http://red.pucp.edu.pe/wp-content/uploads/biblioteca/091108.pdf, acessado em 10/06/2014.

CLAVERO, B. 2010. Instrumentos internacionales sobre los Derechos de los Pueblos Indígenas: Declaración de Naciones Unidas y Convenio de la Organización Internacional del Trabajo. Disponível em http://clavero.derechosindigenas.org/wp-content/uploads/2008/06/prologo-articulo-instrumentos.pdf , acessado em 08/06/2014.

CORBIN, A. 1987. Saberes e odores. São Paulo, Companhia das Letras.

CUGOANO, Q. O. 1999. Thoughts and sentiments on the evil of slavery and other writings. New York, Penguin.

GORDON, L. African-American Philosophy, Race, and the Geography of Reason. Disponível em http:// lewisrgordon.com/selected-articles/africana-philosophy/lewis2.pdf, acessado em 09/06/2014.

MAHMOOD, S.; DANCHIN, P. 2014. Politics of Religious Freedom: Contested Genealogies. South Atlantic Quarterly.

MIGNOLO, W. 2003.The Darker Side of the Renaissance: Literacy, Territoriality, and Colonization. $2^{a}$ ed., University of Michigan Press. Disponível em: http://people.duke.edu/ wmignolo/Interactive$\mathrm{CV} /$ Publications/darker2nded.pdf, acessado em $14 / 06 / 2014$.

MIGNOLO, W. 2008. A desobediência epistêmica: a opção descolonial e o significado da identidade em política. Cadernos de Letras da UFF. Disponível em http://www.uff.br/cadernosdeletrasu$\mathrm{ff} / 34$ /traducao.pdf, acessado em 14/06/2014.
MOYN, S. 2010. The last utopia. Harvard, Harvard College.

SANTOS, B. S.; MENESES, M. P. 2010. Epistemologias do Sul. São Paulo, Cortez.

SANTOS, B. S. Para uma sociologia das ausências e uma sociologia das emergências. Disponível em http://rccs.revues.org/1285\#text, acessado em $14 / 06 / 2014$.

SCOTT, J. W. 2009. Sexularism. Disponível em http://cadmus.eui.eu/bitstream/handle/1814/11553/RSCAS_DL_2009_01. pdf? sequence $=1$, acessado em $15 / 06 / 2014$.

SINHA, V. 2003. Decentring Social Sciences in Practice Through Individual Acts and Choices. Current Sociology, january. 51: 7-26.

STEINER, G.. 2009. Antígonas; la travesía de un mito universal por la historia de Occidente. Barcelona, Gedisa.

ALEJO, E. T. 2011 . Bolivia en el inicio del pachakuti. Madrid, Akal.

ALEJO, E. T. El indianismo de Fausto Reinaga: orígenes, desarrollo y experiencia em Qullasuyu-Bolivia. Quito, Universidad Andina Simón Bolivar. Tesis doctoral. Disponível em http://repositorio. uasb.edu.ec/bitstream/10644/3758/1/TD040-DECLA-Ticona-El\%20indianismo.pdf, acessado em 15/07/2014.

TRUTH, S. 2014. E não sou uma mulher? Disponível em http://www.geledes.org.br/atlantico-negro/ afroamericanos/sojourner-truth/22661-e-nao-sou-uma-mulher-sojourner-truth, acessado em $18 / 07 / 2014$.

VISVANATHAN, S. A celebration of difference: science and democracy in India. Disponível em https: //www.sciy.org/a-celebration-of-difference-science-and-democracy-in-india-by-shiv-visvanathan/, acessado em 20/06/2014.

VISVANATHAN, S. 2009. The search for cognitive justice. Disponível em http://www.india-seminar. com/2009/597/597_shiv_visvanathan.htm, acessado em 15/06/2014

VISVANATHAN, S. 2008. Beyond the social contract: science, knowledge and the democratic imagination in India. Disponível em http://enterqdesigns.com/TeamBHUMN432/docs/35766845. pdf, acessado em 18/07/2014. 